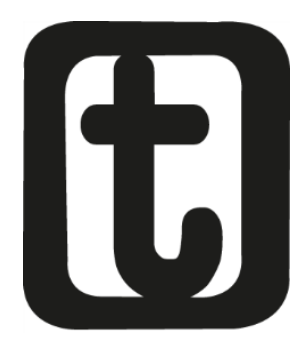

\title{
INTERFACES NO TRABALHO DOS CATADORES DE MATERIAIS RECICLÁVEIS: RELAÇÕES COMPLEXAS COM O ESTADO E O CAPITAL
}

Interfaces in working of recyclable material collectors: complex relationships with the State and the capital

\section{Josimery Amaro de Melo ${ }^{1}$ Jackson Vital Souto ${ }^{2}$}

\section{RESUMO}

Este artigo trata do fenômeno da reciclagem central no debate socioambiental e acadêmico. O objeto principal diz respeito aos processos em que parte dos materiais recicláveis adquire importância para o Estado e para a indústria. Sob modalidades diversas a atividade da coleta/cata de materiais recicláveis tem em comum a disseminação de um discurso: gerar emprego com preservação do ambiente. A pesquisa (obedeceu aos princípios éticos que permeiam os estudos com humanos do Ministério da

\footnotetext{
${ }^{1}$ Assistente Social, Mestre em Serviço Social (UFPB), João Pessoa.

E-mail:<hosimery@gmail.com>.

${ }^{2}$ Geógrafo, Mestre em Administração (UFPB), Mestrando em Geografia (UFPE), sob orientação da $\mathrm{Dr}^{\mathrm{a}}$. Beatriz Maria S. Pontes.

E-mail: <geografandosouto@gmail.com>.
}

Temporalis, Brasilia (DF), ano 11, n.21, p.49-70, jan./jun. 2011. 
Saúde), da qual foi fruto este artigo, realizou-se junto a catadores de materiais recicláveis de duas associações da cidade de João Pessoa (PB), com os quais objetivamos analisar as relações de trabalho destes com o Capital e o Estado. Obtivemos neste estudo grandes descobertas das quais nossa teoria e método de base marxiana foi imprescindível. Preocupamo-nos neste artigo em repor o debate teórico considerando o mergulho necessário na realidade, que trataremos em outro momento.

\section{PALAVRAS-CHAVE}

Trabalho. Recicláveis. Catadores. Capitalismo. Estado.

\section{ABSTRACT}

This article approaches the phenomenon of recycling in socioenvironmental and socio-academic debates. It aims at analyzing the proceedings in which part of the recyclable materials becomes important to the state and the industry. Under several categories, the activity of collecting/searching for recyclable material has the following discourse in common: creating jobs through environmental preservation. This study (following the ethical principles that underlie the Ministry of Health's human studies), from which this article derives, was carried out among associations of recyclable material collection in the City of João Pessoa (PB) to analyze the relationship between these collectors and the state and capital. Our Marxist-based theory and methods were essential to the great findings obtained in this study. In this article, we focus on restoring the theoretical debate considering the necessary dive into reality, which we will approach some other time.

\section{KEYWORDS}

Work. Recyclable materials. Recycling Collectors. Capitalism. State.

Submetido em 30/05/2011

Aceito em 09/09/2011 


\section{tempordils}

MELO, J. A. de; SOUTO, J. V. INTERFACES NO TRABALHO

\section{INTRODUÇÃO}

O trabalho informal hoje se apresenta sob o signo da reestruturação produtiva carregado de noções e apresentando formas variadas e características distintas, mas tendo como lastro a exploração do capital sobre o trabalho, ou seja, apontando que o sistema capitalista não deixa ninguém de fora e absorve trabalho não pago até dos que não tem contrato formal.

Segundo o dicionário (FERREIRA, 2000), informal refere-se a tudo que é “[...] destituído de formalidade; próprio de quem é informal”, confirmando o que convencionalmente o senso comum entende por informalidade. Informal é o que não é formal. É algo dissociado, desmembrado, que não faz parte do mesmo universo, da mesma totalidade. No que se refere à categoria trabalho essa interpretação assume contornos discutíveis e consequentes. No decorrer desse artigo abordaremos a situação dos catadores de resíduos recicláveis, informais que atuam na linha de frente do desenvolvimento do processo produtivo da reciclagem, força de trabalho superexplorada e precarizada que garante o lucro à indústria da reciclagem, portanto do capital, geralmente mediado pelo Estado.

Entendemos formalidade e informalidade compondo um mesmo e único universo, sendo que a primeira é condição garantida aos trabalhadores regularmente contratados conforme um sistema de leis criadas pelo Estado que lhes garante proteção social, enquanto o segundo sofre a total ausência daqueles benefícios. A informalidade é um conceito amplo e envolvem inúmeras atividades, importando ressaltar, no atual desenvolvimento do capitalismo o fato da fragilidade/precarização na condição do trabalho informal a que estão sujeitos os trabalhadores que ingressam no mercado de trabalho.

Temporalis, Brasilia (DF), ano 11, n.21, p.49-70, jan./jun. 2011. 
O trabalho informal existe desde o advento da hegemonia capitalista, especialmente nos países periféricos, mas essa forma de trabalho que se expande sob o signo da flexibilidade já não se restringe às pequenas unidades produtivas que funcionavam sem relação com a produção capitalista, como queria a Organização Internacional do Trabalho (1972). A reestruturação produtiva do capital ao priorizar a flexibilidade como uma das políticas macroeconômicas que orienta a organização da produção propiciou processos de terceirização pelos quais muitas atividades saem do interior das empresas para serem desenvolvidas nos espaços da informalidade. Dado o grande volume de desemprego, resta aos trabalhadores aceitarem as condições impostas pelo capital. Com isso diminui o custo variável da produção, aumenta o capital constante e expande-se o trabalho informal com graves consequências aos trabalhadores. Estes são obrigados a se inserir no mercado de forma insegura, frágil e precário. É nesta perspectiva que Bosi (2008, p.113) aponta: “[...] as ocupações tidas como 'informais' vêm ganhando relevância no mundo do trabalho exatamente porque têm sido acionadas como forma de produção preferencial do capital e não como escolha exclusiva dos trabalhadores".

Realçadas essas questões, percebe-se que, em princípio, o que distinguia o formal do informal corresponderia a normas jurídicas instituídas pelo Estado pelas quais se estabeleciam direitos trabalhistas para o conjunto de trabalhadores formais do campo e das cidades.

Contemporaneamente vivemos a era do toyotismo, que diferente do que aconteceu no taylorismo/fordismo, as relações de trabalho já não se pautam na rigidez de contratos formais regidos pela Consolidação das Leis Trabalhistas (CLT), ficando a sensação da 


\section{tempordilis}

MELO, J. A. de; SOUTO, J. V. INTERFACES NO TRABALHO

segurança no emprego como coisa do passado. Agora cada trabalhador é responsabilizado pelo seu (des)emprego, cabendo ser empreendedor e criar condições de empregabilidade.

Com isso, o trabalho informal assume características novas, diferente daquelas definidas pela OIT (1972). As atividades informais já não se restringem às práticas de fundo de quintal exercidas de forma independente sem articulações diretas com a produção capitalista. Ao contrário, a cooperação capitalista articulou o formal ao informal e ambos participam do processo de produção e de acumulação capitalista. O sistema capitalista hoje se alimenta tanto do excedente produzido pelo trabalho formal quanto do informal seja trabalhadores produtivos ou improdutivos no campo ou nas cidades. Ambos são complementares ao capital (TAVARES, 2004). Ainda segundo esta autora:

No atual nível de desenvolvimento capitalista não há escapatória possível para o trabalhador. Qualquer que seja a sua forma de inserção na produção, está sujeito, direta e indiretamente, às exigências da competição, da produtividade crescente, da acumulação e da extração de sobretrabalho (TAVARES, 2004, p. 145).

O estudo sobre a informalidade enquanto setor econômico surge na academia entre as décadas de 1970 e 1980, com as análises da OIT, das novas práticas de trabalho desenvolvidas em países da periferia do sistema particularmente no ano de 1972, no Quênia país situado justamente numa das regiões mais pobres do mundo. Algumas formulações teóricas mais progressistas ${ }^{3}$, outras mais

${ }^{3}$ A teoria da subordinação foi formulada por Souza (1999 apud TAVARES, 2004, p.36) segundo ele a economia é um continuum de formas de organização da

Temporalis, Brasilia (DF), ano 11, n.21, p.49-70, jan./jun. 2011. 
conservadoras ${ }^{4}$ dão conta do que se interpreta sobre o fenômeno. Após esse momento, arrefecem as discussões no âmbito acadêmico, em contraposição às novas determinações do mercado mundial que tem no movimento do trabalho informal o sinônimo de flexível (TAVARES, 2004) portanto, funcional ao desenvolvimento capitalista. Diante da crise estrutural que reduz o volume de emprego e de posto de trabalho o debate se desloca do campo econômico da contradição capital-trabalho para as políticas de inclusão-exclusão. Ou seja, se desloca da economia para a política. O discurso corrente desagregou-se do caráter econômico para fincar raízes na questão sociopolítica, demandando políticas públicas de inclusão.

Conforme Maranhão (2008, p.95),

Ao resumir a heterogeneidade das teses dos 'teóricos da exclusão', mesmo correndo o risco de generalizações, poderíamos dizer que o que une seu pensamento é a defesa de uma espécie de 'neo contratualismo'. Para eles, a transição de uma sociedade industrial para uma sociedade pósindustrial ou pós-salarial rompeu o 'contrato social'

produção, em que o 'setor informal' não é uma forma isolada, mas sim uma forma de produção integrada e subordinada à produção capitalista.

${ }^{4}$ Trata-se de uma missão de estudos, que analisou o problema do emprego urbano no Quênia, com vistas a um diagnostico e à proposição de políticas para atenuação do desemprego e do subemprego naquela e em outras economias subdesenvolvidas. A noção de setor informal foi utilizada pela primeira vez no relatório resultante dessa Missão. Mas, deve-se ressaltar que Keith Hart já havia utilizado o adjetivo informal num trabalho pioneiro sobre emprego e renda urbana em Gana, em 1971, embora o tenha aplicado na oportunidade à renda e não ao setor. Assim, a concepção básica de setor informal foi estabelecida em Employment, Incomes and Equality: a Strategy forlincreasing Productive Employment in Kenya, Genebra, 1972 (OIT apud TAVARES, 2004). 


\section{temporalis}

MELO, J. A. de; SOUTO, J. V. INTERFACES NO TRABALHO

que vigorou na época do Estado de Bem-Estar e isso gerou uma crise filosófica do Estado, que, por sua vez, tem como consequência a desagregação dos princípios de solidariedade e coesão social.

Nessa perspectiva, a contradição capital-trabalho é coisa do passado. Teria desaparecido a clássica divisão entre explorados e exploradores. Ainda conforme o mesmo autor, para os chamados teóricos da exclusão, “[...] estaríamos vivenciando o aparecimento de uma nova cisão, aquela que opõe de forma abstrata e genérica, incluídos e excluídos" (MARANHÃO, 2008, p.96). Contudo, o desemprego e a precariedade do trabalho informal são fatos históricos concretos que atingem apenas indivíduos de uma classe social heterogênea: a dos trabalhadores no espaço do campo e das cidades. E não se trata de um acontecimento eventual, mas de um fenômeno inerente à produção capitalista, que se amplia no toyotismo, por conta do estágio de desenvolvimento e dos processos de acumulação do capital.

Malgrado as várias acepções e inconstâncias estatísticas sabe-se que hoje os trabalhadores informais estão em todos os espaços, não apenas nos interstícios da formalidade, mas em todos os segmentos econômicos e nos mais diversos países. Enfim, a acumulação flexível, marca dos processos de reestruturação do capital, comporta um trabalho informal de novas feições, cuja dependência e precarização estão na base da relação social do capital.

Nosso estudo pressupõe a concepção de trabalho informal oferecida por Tavares (2004, p.52), que esclarece:

[...] trata-se do emprego desprotegido, sem vinculo formal, mais diretamente vinculado à produção capitalista. Trata-se de formas de trabalho que foram praticadas pela sociedade pré-industrial e são agora

Temporalis, Brasilia (DF), ano 11, n.21, p.49-70, jan./jun. 2011. 
retomadas pela empresa, que tende a deixar de ser lugar por excelência da chamada relação salarial moderna.

Imbricada ou diluída na noção geral de informalidade existe atividades de estrita garantia da reprodução social exercidas por trabalhadores desempregados pobres prestadores de serviços, venda e revenda de mercadorias. Também existem aquelas atividades que estão articuladas à produção capitalista de forma vertical e/ou horizontal no campo e nas cidades. São essas que merecem ser investigadas. Neste sentido, propomos discutir os informais catadores de recicláveis que exercem um trabalho informal diretamente articulado à produção capitalista, na medida em que os materiais coletados se constituem matéria-prima para a produção de novas mercadorias. O Estado por sua vez, ao apoiar e mediar atividades dessa natureza contribui para manipular ideologicamente com dados os altos níveis de desemprego e passa a disseminar a idéia de autonomia no trabalho, tão cara aos que defendem a flexibilidade da economia, geralmente fazendo crer que o trabalho informal é opção dos trabalhadores e não imposição da totalidade do sistema do capital.

A reciclagem de resíduos sólidos, na atual escala de concorrência global entre monopólios transnacionais e rearranjos na composição orgânica do capital, é receita de marketing que o capital (re) cria para anunciar que respeita, promove e se reproduz em um ambiente sadio, seguro e justo. No entanto, o motor desse negócio é o lucro. E pela natureza da atividade, são exatamente os sujeitos a quem não resta mais nenhuma alternativa de ingresso e ocupação no mercado de trabalho, que vão ser explorados informalmente pelo capital. E este ganha duplamente com a cata de recicláveis e com a diminuição dos gastos que teria com energia, água e a matéria-prima in natura, fontes naturais e substanciais na 


\section{tempordilis}

MELO, J. A. de; SOUTO, J. V. INTERFACES NO TRABALHO

criação de suas mercadorias. Segundo Bosi (2008, p.102) “[...] o trabalho dos catadores de recicláveis no Brasil está integrado ao processo de acumulação de capital e que a suposta situação de exclusão dos catadores (desempregados, baixa escolaridade, faixa etária elevada) o qualifica para esse tipo de ocupação".

Considerando que a atividade do catador de recicláveis interessa diretamente ao capital indústria, temos nos perguntado se não seria mais justo o Estado levar o conjunto dos trabalhadores para a formalização do trabalho. Observamos que quando uma atividade produtiva é desenvolvida na pequena escala ou da microempresa e passa da informalidade à formalidade, o discurso dos agentes do Estado e as verbas são recorrentes e a favor da formalização. Os catadores inseridos no quadro de pobreza ampla e geral parece não ser parte da economia, sendo portanto, inseridos entre aqueles para os quais o trabalho informal é entendido como política. Desse modo,

[...] atividades que se encontram nessa categoria se expandem e são recomendadas por organismos financeiros internacionais como uma ação política temporária, até que o ajuste promovido pela reestruturação produtiva apresente os frutos esperados (TAVARES, 2004, p.153).

Cabe perguntar: por que a produção, cuja matéria-prima é o material reciclável, se insere na economia e a atividade do catador se insere na política de assistência aos pobres? Afinal, não dá mais para negar que o trabalho informal faz parte da produção capitalista. 


\section{DESENVOLVIMENTO}

Atualmente, apesar do aumento da informalidade e da funcionalidade ao capital, tenta-se obscurecer o trabalho informal através de novas denominações atribuídas a essa modalidade de exploração que consubstancia a era flexível. Os termos mais comuns são empreendedorismo e empregabilidade. Diluída nessa idéia encontra-se a justificativa para o fim da contradição capitaltrabalho, germinando iniciativas individuais na figura do pequeno empreendedor, patrão de si mesmo, o que dissolve a sociedade de classes em um mundo de iguais, com todos podendo ser patrões e cidadãos de si mesmo. Trata-se da capacidade de auferir renda, por conta própria, ficando a cargo do trabalhador se manter e garantir a reprodução da sua família, com a renda produzida em seu empreendimento. Caso isso não ocorra, a culpa é de sua incapacidade de administrar o próprio negócio ou ainda falta de competência, e não do sistema. Destarte, nega-se o valor do trabalho como produtor de riqueza nos espaços das cidades e do campo.

Segundo Cacciamali (1999, p.382), a empregabilidade é uma alternativa à miséria empreendida por aqueles que têm dificuldades de ingresso no mercado de trabalho e com renda familiar baixa, insuficiente para subsistência. Para a mesma autora, "[...] esse grupo caracteriza-se pelo fato de compreender indivíduos que são simultaneamente patrões e empregados de si mesmos, podendo engajar familiares ou assalariados nesse processo".

Os trabalhadores informais podem atender ao sistema de forma direta e indireta. Estes, embora sem nenhuma das garantias do trabalho formal (direitos trabalhistas) podem produzir mais-valia para 


\section{tempordilis}

MELO, J. A. de; SOUTO, J. V. INTERFACES NO TRABALHO

o capitalista, em ambientes não vinculados à fábrica, da mesma forma que o trabalhador formal. A esse respeito Tavares (2004, p.99) brilhantemente reflete:

[...] há uma forma de trabalho que valoriza o capital,
a qual coexiste com outra que mesmo não o
valorizando, lhe é necessária. Falávamos da inter-
relação do trabalho produtivo com o improdutivo,
duas formas que se complementam, a primeira na
esfera da produção, e a segunda na esfera da
circulação.

Entende-se que a concepção de informalidade por nós adotada garante a possibilidade de apreender os nexos existentes na relação entre os catadores de recicláveis, as indústrias que utilizam os materiais coletados e o Estado. A atividade dos catadores, a exemplo de outros trabalhos informais, expressa a emergência do sistema capitalista de produção, seus reordenamentos, enxugamentos, atrofias e hipertrofias produzidas pelo capital, suas instituições e agentes, enquanto exigências capazes de conceder maior fôlego ao sistema do capital.

O Estado, nesse processo, aparentemente se coloca em defesa dos interesses coletivos dos catadores, até porque eles são a parte mais frágil da relação. Para o senso comum, mas não só, é o trabalho que precisa do capital e não o capital que precisa de trabalho. Sendo assim, os catadores de recicláveis é que estão sendo ajudados, na medida em que o Município Ihes fornece os instrumentos de trabalho e ainda participa diretamente da venda dos materiais coletados. Dentre outras ideologias disseminadas pelo aparato institucional do Estado, é possível supor que os catadores são pessoas de baixa escolaridade cujo acesso à indústria seria dificultado pelas inúmeras diferenças que existem entre o catador e os gestores da indústria. Assim, em lugar de promover a autonomia, concepção defendida pelo Estado burguês, 
contraditoriamente, o município tutela a relação social. O que nos parece é que a relação capital-trabalho no que se refere aos catadores de recicláveis, confirma o pensamento marxista acerca do Estado moderno, quando afirma que este é um comitê para os negócios da burguesia (MARX; ENGELS, 2001, p. 27). Daí se impõe conhecer o Estado e suas funções na mediação da relação capital-trabalho.

O sistema capitalista foi ontologicamente criticado por Karl Marx no século XIX, e seus estudos permitem analisar a sociedade capitalista até os dias atuais. Na contemporaneidade, os conflitos se cristalizam de forma mais perversa quando as contradições são exacerbadas, à medida que frações dos trabalhadores têm sido expulsa do mercado formal de trabalho e expropriada das terras de trabalho para serem mais duramente explorados, agora informalmente. Estes dão origem a uma categoria de trabalhadores informais, que participa do processo de acumulação capitalista, como defende Tavares (2004). A nosso ver, faz parte dessa informalidade uma forma de trabalho típica do atual momento histórico: o catador de resíduos recicláveis.

A questão do lixo e do tratamento adequado dos resíduos sólidos e líquidos é um problema mundial, mormente quando já se anunciou a crise ecológica e os efeitos por ela trazidos para o ar, massas de água, fertilidade da terra e biosfera em sua totalidade. Surge dessa problemática várias questões de reordenamento do metabolismo sócio-natural controlado pelo capital, dentre elas: como destinar o lixo produzido na sociedade especialmente nas cidades. Reciclar tem sido a saída. Para que esse fenômeno se propague e se desenvolva, promovendo um novo lucro ao capital é necessária a exploração do catador de resíduos recicláveis, artífice principal da cadeia produtiva da reciclagem: coleta, transformação e retorno ao mercado com novo valor de troca. 


\section{tempordilis}

MELO, J. A. de; SOUTO, J. V. INTERFACES NO TRABALHO

Não nos parece que o modo de produção capitalista visa extinguir as causas de uma possível questão ecológica muito pelo contrário foi neste modo de produção numa escala planetária de produção de mercadorias que essa questão foi produzida. E, na solução dos efeitos o capital e os Estados conseguem adquirir bônus e créditos de carbono diversos, inclusive com o selo verde e a alcunha de amigo da natureza, negociados nas bolsas de valores.

Já não restam dúvidas quanto ao interesse do capital industrial pelos recicláveis, uma vez que estes substituem determinadas matériasprimas, com as seguintes vantagens na composição orgânica do capital: podem ser adquiridos e produzidos por um custo de produção mais baixo e, ainda permitem ao capital propagar seu protagonismo no chamado desenvolvimento sustentável gerando emprego para uma população sem quaisquer chances de ingresso no mercado de trabalho, revelando a face da responsabilidade social da produção capitalista, que tenta se legitimar como a última organização por excelência da história da humanidade.

Os catadores de resíduos recicláveis estão entre os trabalhadores que constituem essa nova informalidade 5 . Desprovidos de quaisquer meios para a mera sobrevivência vão à busca de resíduos da produção capitalista, objetos que depois de passarem pelo lixo são novamente devolvidos à população em forma de mercadorias, assim esta atividade demonstra funcionalidade à produção capitalista. Contudo, o uso dessa força de trabalho tem sido tratado pelo conjunto mais amplo da sociedade como se fosse uma benesse do Estado e do capital.

${ }^{5}$ Objeto de estudo de Tavares (2004).

Temporalis, Brasilia (DF), ano 11, n.21, p.49-70, jan./jun. 2011. 


\section{PRODUÇÃO DESTRUTIVA E RECICLAGEM}

Estudiosos de varias especialidades vêm pensando em soluções para minorar os processos de degradação dos ecossistemas e precarização do mundo do trabalho em nosso planeta. No entanto, o modo de produção capitalista encontra barreiras e limites a certas medidas por considerar alto o custo financeiro que 0 tratamento adequado ao lixo impõe, já que parte das soluções propostas atinge diretamente os processos produtivos. A saída de menor risco e custo encontrados, pelo menos no que tange ao lixo, foi a reciclagem. Idealmente, trata-se de uma forma lucrativa utilizada pelo capital para dar um destino salutar ao lixo e poder garantir uma melhor qualidade de vida a frações da burguesia na sociedade moderna, que são consumidores ativos em velocidade e abundância extrema especialmente na periferia do sistema. Ledo engano achar que os agentes do modo de produção capitalista viram na reciclagem apenas a possibilidade de uma melhor qualidade de vida para o conjunto da sociedade, quando na verdade o capital está usurpando da natureza sua riqueza em seu benefício, pois seu principal objetivo é acumulação e o lucro.

A reciclagem nasce para o capital com a finalidade do lucro, a mercadoria que é consumida e descartada retorna às indústrias nas formas de plástico, papel, vidro, metal, alumínio etc., e é reutilizada e reaproveitada como matéria prima reciclável transformada numa nova mercadoria, propiciando nova extração de mais-valia e garantia de lucro para a produção capitalista. O uso da força de trabalho do catador garante ganhos ao capital e o legitima, na medida em que graças a esse processo são propagadas a geração de emprego e renda e a preservação do meio-ambiente. Não se alude ao processo de trabalho que na verdade está ocorrendo 


\title{
tempordils
}

MELO, J. A. de; SOUTO, J. V. INTERFACES NO TRABALHO

originalmente o movimento destrutivo do ambiente e a manutenção do desemprego, agora estrutural.

\begin{abstract}
A reciclagem vista como possibilidade de recuperação lucrativa dos resíduos sólidos para o circuito do consumo das mercadorias, nos conduz a uma desmistificação com relação aos ganhos ambientais por ela proporcionados, já que, [...] o seu principal estímulo é a obtenção do lucro e não a preservação ambiental, que para a sociedade que esta sob a égide do capital é uma situação contraditória, pois como preservar e estimular o consumo ao mesmo tempo? (LEAL et al. 2002, p. 179).
\end{abstract}

O catador é explorado duplamente em dois momentos e espaços, pelo capital e pelo Estado. Inserido na informalidade tem que vender seus achados a preços irrisórios, enquanto o atravessador repassa a mercadoria com um valor adicionado à indústria que, por sua vez transforma a mercadoria descartada em um novo produto comercializável e com um sobrevalor agregado. Entrecruzam-se o valor de uso e o valor de troca: a mercadoria reciclada que antes já foi valor de uso, adquirida pela troca, volta a ser valor de uso pela interferência mágica de tornar-se novamente valor de troca e retornar ao mercado.

As mercadorias vêm ao mundo sob a forma de valores de uso ou de corpos de mercadorias, como ferro, linho, trigo etc. Essa é a sua forma natural com que estamos habituados. Elas só são mercadorias, entretanto, devido à sua duplicidade, objetos de uso e simultaneamente portadores de valor. Elas aparecem, por isso, como mercadoria ou possuem a forma de mercadoria apenas na medida em que possuem forma dupla, forma natural e forma de valor (MARX, 1988, p. 53).

Temporalis, Brasilia (DF), ano 11, n.21, p.49-70, jan./jun. 2011. 
Os materiais recicláveis só interessam ao capital porque carregam a possibilidade de tornar-se valor de uso enquanto suporte ao valor de troca. Sem que disso tenha consciência, o catador co-participa simultaneamente do processo de limpeza urbana e também do processo de produção capitalista. No entanto, não é reconhecido nem como agente do Estado nem do capital. No máximo, os catadores são reunidos em associações pelo Estado para servirem ao capital. O que sabem eles sobre essa organização social? E sobre seus direitos sociais, sua vinculação ou (des) vinculação ao mercado informal/formal?

O fenômeno da reciclagem proporcionou um aumento do contingente populacional que vive da cata do lixo. No ano de 2001, estimava-se que 500 mil pessoas catavam lixo no Brasil, segundo Mota (2002, p. 10). Hoje, informações da Cáritas brasileira e do Movimento Nacional dos Catadores (MNC), dão conta que esse número aumentou para 800.000 mil pessoas e na cidade de João Pessoa informações da Autarquia Especial de Limpeza Urbana (EMLUR), apontam para aproximadamente duas mil pessoas vivendo da coleta de recicláveis.

Os catadores estão na ponta do processo de reciclagem, que começa na rua e termina na fábrica. De acordo com Mota (2002) há uma espoliação destes trabalhadores que na informalidade obedecem às regras do mercado e do Estado, mesmo não estando vinculados diretamente a nenhum dos dois. "O trabalhador de rua materializa na sua atividade um trabalho duplamente explorado, pelas empresas de reciclagem e pelo próprio Estado" (MOTA, 2002, p. 19). O Estado através das instituições urbanas públicas, sob o discurso da preservação ambiental ou da política social, media esse processo de produção de mercadorias. "Ao fazê-lo também estas 


\title{
tempordilis
}

MELO, J. A. de; SOUTO, J. V. INTERFACES NO TRABALHO

instituições se apropriam do trabalho do catador de lixo, integrandoos aos serviços de limpeza urbana" (MOTA, 2002, p. 10).

\begin{abstract}
Por entendermos que a crise ambiental é determinada pela natureza da produção capitalista, consideramos que as medidas voltadas para seu enfrentamento longe de estabelecer limites à produção destrutiva, revelam a tendência de transformá-la numa destruição produtiva [...], a administração de suas sequelas consolidam novas estratégias de acumulação (MÉSZAROS apud MOTA, 2002, p. 11).
\end{abstract}

A ânsia desenfreada pelo lucro é um movimento imerso de contradições que exaure da natureza suas riquezas, provocando um medo eminente de um dia estes recursos naturais não serem mais acessíveis. Teria sido este um fator de aceleração do uso de recicláveis na indústria dos reciclados? De repente o capital teria passado a se preocupar com o futuro do planeta? Ou, confirmando a sua velha lógica, usar os recicláveis é garantia de maiores níveis de acumulação exigência do momento pós-reestruturação produtiva? O que parece é que para o mercado reciclar significa além de ganhar concorrencialmente, também obter créditos no quesito gestão da qualidade socioambiental.

Neste contexto em que por um lado a dialética sociedade-natureza degradada clama urgente por novas relações sociais e, por outro, a indústria que no processo de reprodução ampliada do capital (re) utiliza os materiais recicláveis é que surgem os catadores. Esse sujeito tem crescido gradativamente nas grandes, médias e pequenas cidades, formando assim uma fração distinta da classe trabalhadora, que catando recicláveis nas ruas, a fim de viabilizar a transformação destes em novas mercadorias para o capital,

Temporalis, Brasilia (DF), ano 11, n.21, p.49-70, jan./jun. 2011. 
consegue, embora de forma precária, comprar as mercadorias que se constituem valores de uso necessários à sua sobrevivência.

\title{
4 ENTRE O CAPITAL E O TRABALHO, A QUEM SERVE O ESTADO?
}

É notório que o Estado atuou como protagonista no resgate do capital em todas as suas históricas crises. Nessa perspectiva, evidencia-se um de seus princípios classistas, qual seja aderir à hegemonia do capital, tanto criando um aparato jurista que dá legalidade às práticas capitalistas que controla as tensões sociais bem como facilitando as relações entre capital e trabalho, através das suas instituições. Sobretudo nos momentos de crise essa função do Estado se agudiza. Mandel (1985, p.340) afirma a funcionalidade do Estado ao capital, quando diz:

\begin{abstract}
[...] a ‘administração das crises' é uma função tão vital do Estado na sua fase tardia do capitalismo quando sua responsabilidade por um volume enorme de 'condições gerais de produção' ou quando seus esforços para assegurar uma valorização mais rápida do capital excedente. Economicamente falando, essa 'administração das crises' inclui todo um arsenal das políticas governamentais anticíclicas, cujo objetivo é evitar, ou pelo menos adiar tanto quanto possível, o retorno de quedas bruscas e catastróficas como a de 1929 e 1932. Socialmente falando, ela envolve esforço permanente para impedir à crise cada vez mais grave das relações de produção capitalistas por meio de um ataque sistemático a consciência de classe do proletariado.
\end{abstract}

O Estado na gestão das crises torna-se imprescindível e um ardiloso administrador. Suas políticas são ideologicamente incrustadas na consciência do trabalhador; sem estas a possibilidade de manutenção do sistema seria quase nula, o Estado capitalista é o 


\section{tempordils}

MELO, J. A. de; SOUTO, J. V. INTERFACES NO TRABALHO

grande repositor da ordem e da paz social, do equilíbrio do sistema mediando os conflitos de classe e os lucros do capital. Logo, podese inferir que este é responsável pelo equilíbrio na dinâmica do processo de organização do trabalho, desde a sua gênese até os dias atuais quando desenvolvimento é concomitante ao aprofundamento da questão social e a produção de novas contradições como a questão ecológica.

Hoje, o desemprego é um problema que atinge o mundo todo desde o centro do sistema a periferia e entre os desempregados que se amontoam nas ruas das grandes e pequenas cidades encontram-se os que são transformados em catadores de recicláveis. A atividade produtiva se desenvolve em condições de ampliação degradante e precária das condições de reprodução do metabolismo social, embora responda a interesses diretos do capital.

O desemprego e o trabalho informal precarizado são expressões da questão social, das quais decorrem muitas outras, pois se a única mercadoria vendável do trabalhador é a sua força de trabalho e ele não tem a quem vendê-la, suas chances de sobrevivência e reprodução social ficam interditadas. O capital se vale da sua dominação e dos processos de fragmentação do trabalho para impor aos trabalhadores atividades degradantes como trabalhar no lixo, ambulantes, flanelinhas, domésticas diaristas e outras tantas, a maioria delas na informalidade. No entanto, nunca se falou tanto de autonomia, parcerias, independência, comércio justo e solidário, autogestão e livre associação como se estas práticas no interior do sistema não estivessem subordinadas aos ditames do capital. A realidade ao contrário, demonstra que não existe autonomia nem tampouco condições materiais e de existência para emancipação humana, no

Temporalis, Brasilia (DF), ano 11, n.21, p.49-70, jan./jun. 2011. 
interior do sistema capitalista, e que todas estas tentativas são oferecidas aos trabalhadores do campo e das cidades, para atender em toda a sua plenitude aos interesses do capital.

\section{CONCLUSÃO}

No caso em debate, não parece que o Estado assuma a perspectiva do trabalho e tampouco busque romper com o sistema. Historicamente, o Estado trata de manter a ordem, a segurança e a propriedade privada e, nem de longe, permite aos trabalhadores se conscientizarem da sua função na sociedade capitalista, menos ainda nos nexos existentes entre a sua atividade e os ganhos do capital. Segundo Marx e Engels (2001, p.120) "[...] às sociedades cooperativas e [associativas] atuais estas só têm valor enquanto são criações independentes, realizadas pelos trabalhadores e não são protegidas nem pelos governos nem pelos burgueses".

Que espécie de associativismo se pratica na relação entre Estadocatadores? Por que os catadores não se associam livremente? Por que não são capacitados a defender os seus interesses sozinhos, mesmo dentro da lógica burguesa? Todas essas perguntas permeiam nosso trabalho e suscitam algumas respostas, no entanto, neste momento, o que se objetiva é oportunizar apenas uma profícua discussão. Diante do exposto, pode-se afirmar apenas que o associativismo burguês não pretende a promoção humana e que, o Estado inserido neste processo os resultados de sua ação podem ser quaisquer outros, menos a livre associação ou emancipação da sociedade. O desemprego, o trabalho informal e precarizado são expressões da questão social, da qual decorrem muitas outras, pois se a única mercadoria que o trabalhador dispõe é a sua força de trabalho e ele não tem a quem vendê-la, a luta pela reprodução é interditada. O capital se vale da sua dominação para impor aos trabalhadores atividades degradantes como trabalhar no 


\section{tempordils}

MELO, J. A. de; SOUTO, J. V. INTERFACES NO TRABALHO

lixo e outras tantas, a maioria na informalidade. No entanto, tais práticas são realizadas sob a designação de autonomia e de livre associação.

As associações de catadores vêm sendo constituídas pelo Estado e por ele mantidas. Fala-se de autonomia dos catadores, mas esta é questionável, mesmo do ponto de vista do que se convenciona como tal. Pois a administração pública está em todos os espaços que chegaram os catadores.

\section{REFERÊNCIAS}

BOSI, A. de P. A organização capitalista do trabalho "informal": O caso dos catadores de recicláveis. Revista Brasileira de Ciências Sociais, São Paulo, v. 23. n. 67, p.101, jun. 2008.

CACCIAMALI, M. C. Globalização, informalidade e mercado de trabalho. In: ENCONTRO REGIONAL DA ABET, 1. 1999. João Pessoa. Anais do $2^{\circ}$ Encontro Regional da ABET em João Pessoa: PPGS, 1999. v. 1.

FERREIRA, A. B de H. O minidicionário da língua portuguesa. 4. ed. Rio de Janeiro: Nova Fronteira, 2000.

LEAL, A. et. al. A reinserção do lixo na sociedade do capital: uma contribuição ao entendimento do trabalho na catação e na reciclagem. Revista Terra Livre, São Paulo, ano 18, n. 19, p. 177, jul./dez. 2002.

MANDEL, E. O Capitalismo tardio. 2. ed. São Paulo: Nova Cultural, 1985 .

Temporalis, Brasilia (DF), ano 11, n.21, p.49-70, jan./jun. 2011. 
MARANHÃO, C. H. Acumulação, trabalho e superpopulação: crítica ao conceito de exclusão social. In: MOTA, A. E. (Org.). 0 mito da Assistência Social: ensaios sobre Estado, política e sociedade. São Paulo: Cortez, 2008. p.93.

MARX, K. O capital. São Paulo: Nova Cultural, 1988. v. I, Livro I.

MARX, K; ENGELS, F. Manifesto do Partido Comunista. Porto Alegre: L\&PM, 2001.

MOTA, A. E. Entre a Rua e a Fábrica: Reciclagem e Trabalho Precário. Temporalis, Brasília, ano 3, n. 6, p. 9, jul./dez. 2002.

OIT. Employment, income and equality: a strategy for increasing employment in Kenya. Geneve: OIT, 1972.

TAVARES, M. A. Os fios (in)visíveis da produção capitalista: informalidade e precarização do trabalho. São Paulo: Cortez, 2004. 